\title{
The Whole is ALL of the Parts, Together
}

\author{
Marvin L. Birnbaum, MD, PhD
}

I have increasing concern that prehospital emergency medical services (EMS) are becoming fractionated. Many providers have formed or are in the process of forming new organizations to meet needs that are perceived as not being met by the organizations currently in place in the EMS community. The issue is not whether the current organizations are able to meet these needs, it is the perception that they are not being met. The inherent danger in the factionalization of prehospital EMS is that the discipline may be sucked into the parochialism that plagues the rest of the medical world. If we look to the other subspecialized disciplines of medicine as a model and mimic their failures, we too shall fail.

Prehospital EMS is distinct from other branches of medical care in that it truly is interdisciplinary. No other area of health care is comprised of persons of such different backgrounds and training. These special people provide the best care possible at a remarkably low cost with a profound commitment to help their neighbors, friends, and community.

Each EMS SYSTEM is comprised of many parts, like the fibers comprising a rope. All-in-all, the predominant reason that EMS systems work is that each of the parts is mutually dependent. The SYSTEM coordinates all of its component parts. The SYSTEM is sustained by close ties and mutual respect between and among the components. Common purpose and communications not present in any other branches of medicine link each of the components. The SYSTEM forms the foundation of prehospital EMS. It is the SYSTEM that distinguishes EMS in the medical community.

To understand the current problem, it is important to view each component strand from the perspective of how it came into existence: each arose in answer to a perceived need, independent from stimulation or leadership by any of the other parts. Ambulance providers arose without the stimulation or leadership from the physician community. Initially, training of personnel was minimal, but later became mandatory, often at the state level-without significant physician involvement. Education was provided by instructors often selected by default. Each part fended for itself. Each struggled for its own survival and for recognition. Each formed with little regard to the SYSTEM in which it had to function. Complete, functional systems were conceived and implemented only in exceptional circumstances. The EMS forest was planted, germination had occurred, and growth was underway. Similar patterns arose all over the world.

Centralized offices were a reaction to the many helter-skelter services in an effort to splice existing pieces into a rudimentary system. Functional systems came later. Since there was a general lack of medical input and commitment, government found itself in the position of having to mandate standards by regulation. Thus, intense rigidity became the rule. The EMTs, paramedics, nurses, physicians, pilots, educators, administrators, firefighters, and the others came to meet most of their respective needs independently from the others.

Since each struggled long and hard for identity, each component continues to try to function independently so as to remain true to its original ideals. Therefore, each has come to view all of EMS parochially, often with little regard to the other components with which it has been forced through regulations to function within the "system." Only recently have there been attempts to integrate all of the component parts into comprehensive EMS Systems, and these attempts often have been a series of heroic struggles. But, systems did evolve and persons with common interests bonded together. And, in the United States, EMS Systems developed at all governmental levels.

But, when a segment of one of these groups felt that its needs were not being heard, there occurred a movement to form a new organization that hopefully would meet its perceived needs better than did the parent organization: an organization in which the participants should have had an active part, but one in which they perceived that they never could play a meaningful role. The National Association of Emergency Medical Services Physicians (NAEMSP) came to be in this fashion. Prehospital emergency physicians who were (and most still are) members of the American College of Emergency Physicians (ACEP) believed that ACEP was not meeting the needs of the prehospital physicians and formed a new, separate organization with its own goals 
and structure. Of further note is the pervasive drive of many academicians to form groups separate and distinct from those of the clinicians. The formation of the University Academic Emergency Medical Services (now the Society for Academic Emergency Medicine [SAEM]) characterizes this type of development. The parent paid inadequate attention to its children and the family split. The kids ran away!

This story has been repeated again and again. But, the subgroups are subspecializing more and more, each with a smaller base of supporters, organized by specific narrow sets of interests rather than by the overall delivery of prehospital emergency medical care. Today, the EMS educators are forming a new organization because they perceive their needs are not being met by any of the existing EMS organizations. The flight physicians are organizing separately from other emergency and prehospital physicians; and on and on it goes-more trees cut down and new fences go up in the forest of EMS. This pattern has occurred in every other branch of medical care. Such factionalism characterizes each of the other disciplines of medicine and has led to difficulty identifying patient advocates. Lack of advocacy is one reason underlying the uncomfortable position in which medicine in the United States finds itself today.

It is important to recognize that each strand of EMS has some needs that are specific to the group forming the new organization. For example, many problems encountered by the helicopter pilots are specific to piloting a medical helicopter; many problems encountered by helicopter crews seem distinct from those which occur in other parts of the prehospital EMS system. Yet, experiences and problems that seem specific to the air-medical component of the prehospital EMS system impact upon the other strands of the EMS system and must be shared with those groups that have similar interests and problems. The same can be said of EMS educators, some of whose many needs are specific to the educational process. But EMS educators must train people to function within an EMS system. Most of the problems are common to all EMS providers: each component is an integral part of the whole EMS system and to be effective, the entire profession must be aware of the problems others encounter because the solutions to individual problems affect the other components of the system. And, the strength of the EMS rope lies in the integrated processes provided by the system and the cooperation between the respective segments.

There is a potential danger if each component of the EMS system peels away from the rest of the EMS community and tries to mark its own territory: "Stay out-it's mine-and, mine is too unique for you to understand." In the process, we increase the risk of falling prey to the divisive subspecialization that plagues the rest of the U.S. health care system. Our common interests, goals, and experiences make EMS a unique entity in the medical community. We provide universal access to optimal care at the lowest possible cost. Others should look to us as the example for delivery of accessible, cost-effective health care. The American colonies once made a choice and their rallying cry was Join or Die. All of the components of EMS must come together now, or whither away in independence, divorced from their natural, professional, and historic allies. We can preserve the independence of our vital components in a manner that shares what is common to us all: our victories, our problems, our ideals, and our dedication.

We need to meet together under a common banner and continue to learn from each other. The scope of the current organizations must and can widen to become more inclusive. The World Association for Emergency and Disaster Medicine (WAEDM) is pursuing this goal at the international level through the formation of the International Federation for Emergency and Disaster Medicine. Societies across the world with similar goals and interests should join this Federation so they all can share and contribute to our combined experience and vision. The time is at hand to build a new union. The NAEMSP can work to splice together the many strands of the U.S. EMS profession to form a strong rope that can bind our individual needs to our common purposes. The leaders are at hand, let us join and thrive. Together we stand, divided we fall. 


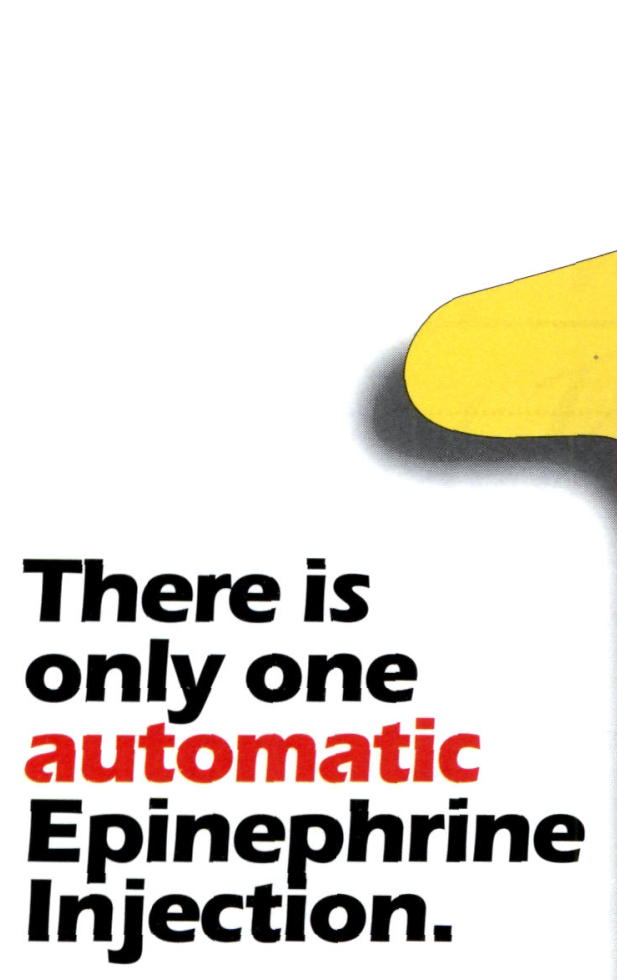

For self administration in any allergic emergency...

Epipen

EPINEPHRINE AUTO-INJECTORS

\section{Just remove safety cap and press into thigh.}

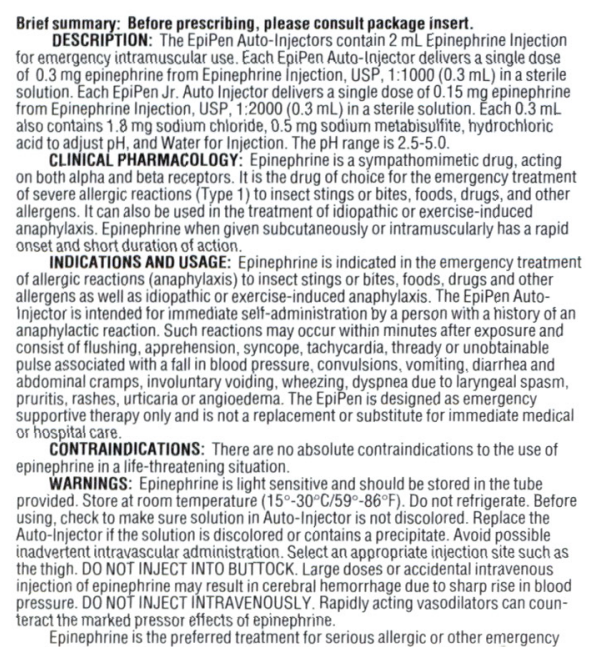

situations even though this product contains sodium metabisulfite, a
sulfite that may in other products cause allergic-type reactions including ana-

sulfite that may in other products cause allergic-type reactions including ana-
phylactic symptoms or life-threatening or less severe asthmatic episodes in certain susceptible persons. The alternatives to using epinephrine in a life-threatening situation may not be satisfactory. The presence of a sulfite in this product should not deter
administration of the drug for treatment of serious allergic or other emergency situations. Accidental injection into the hands or feet may result in loss of blood flow to the affected area and should be avoided. If there is an accidental i ijection into these areas,
go immediately to the nearest emeryency room for treatment. EpiPen should ONL $Y$ be injected into the anteriolateral aspect of the thigh.

administered with extreme caution to patients who have heart disease. Use of epinephrine with drugs that may sensitiz the trean to anmymias, e.g. digitalis, mercurial diuretics, or quinidine, ordinarily coronary insufficiency. The effects of epinephrine may be potentiated by tricyclic monoamine oxidase inhibitors. Hyperthyroid individuals, pregnant women, and children under $30 \mathrm{~kg}$ (66 lbs.) body weight may be theoretically at greater risk of developing adverse reactions after epinephrine administration. Despite these concerns, epinephrine is essential for the treatment of anaphylaxis.
Therefore, patients with these conditions, and/or any other person who might be in position to administer EpiPen or EpiPen Jr. to a patient experiencing anaphylaxis
should be carefully instructed in regard to the circumstances under which this lifeCARCINOGENESIS, MUTAGENESIS, IMPAIRMENT OF FERTILITY: Studies O epinephrine in animals to evaluate the carcinogenic and mutagenic potential or the epinect on fertility have not been conducted.

USAGE IN PREGNANCY: Pregnancy Category C: Epinephrine has been shown to be teratogenic in rats when given in doses about 25 times the human dose. There are no adequate and well-controlled studies in pregnant women. Epinephrine should be
used during pregnancy only if the potential benefiti justifies the potential risk to the

fetUS. PEDIATRIC USE: Epinephrine may be given safely to children at a dosage appropriate to body weight (see Dosage and Administration)

ADERSE REACTIONS: Side efiects of epinephrine may include palpitations. weakness, tremor, headache and anxiety. Cardiac arrythmias may follow administration of OVERDOSAGE: Overdosage or inadvertent intravascular injection

f epinephrine may cause cerebral hemorrhage resulting from a sharp rise in bloo pressure. Fatalities may also result from pulmonary ed
vascular constriction together with cardiac stimulation.

DOSAGE AND ADMINISTRATION: Usual epinephrine adult dose for allergic emergencies is $0.3 \mathrm{mg}$. For pediatric use, the appropriate dosage may be 0.15 or 0.3 . body weight of the patient. However, the prescribing physi政 the reactions for which this drug is being prescribed. With severe persistant anaphy.

and EpiPen Jr. Auto-Injectors are available singly or in CAUTION: Federal (U.S.A.) law prohibits dispensing without a prescription.
Issued: April 1992

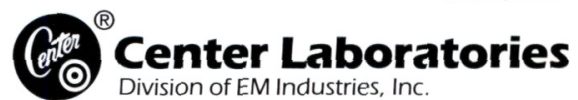

35 Channel Drive, Port Washington, NY 11050 Tel. 800-2-CENTER or 516-767-1800 Distributed in Canada by Allerex Laboratories, Lto. Kanata, Ontario. Tel. 613-592-8200

Manufactured for Center Laboratories by

Survival Technology, Inc. Rockville, MD 20850
U. Patent Nos 3.882, $863,4,031.893$ and 3.712 .301 


\section{LifeDefense Plus from Matrx The New Standard in Defibrillator/Monitor/Pacers}

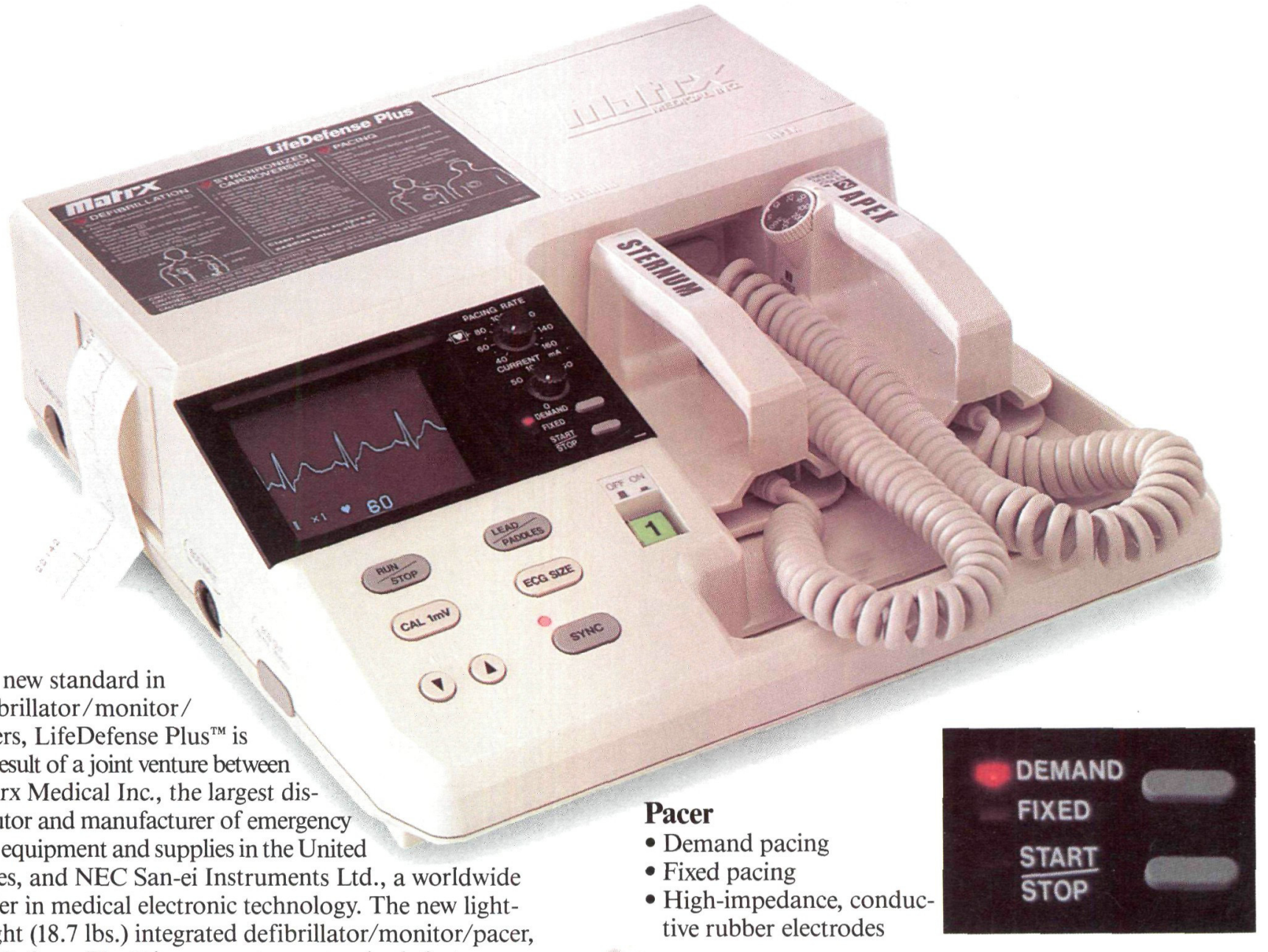

weight (18.7 lbs.) integrated defibrillator/monitor/pacer, LifeDefense Plus ${ }^{\mathrm{TM}}$ incorporates as standard, features that other units offer only as options.

\section{Defibrillator}

- Impedance indicator on paddle

- Energy setting on paddle

- Remote defibrillation

- Synchronized cardioversion

- Automatic recording of defibrillation event

- Pediatric paddle adapters

\section{Monitor}

- Large 7 sq. in. Sony ${ }^{\star}$ CRT screen

- Direct monitoring from ECG electrodes, paddles, or defibrillation electrodes

- Audio/visual message system

- Real/delay recording modes

- Annotated messages on

Z-fold thermal paper

\section{Battery support/accessories}

- High-capacity 2.2 amp hour NiCad battery

- Multiple-function battery support system

- Full complement of quality Matrx accessories

For more information and a demonstration of LifeDefense Plus ${ }^{\mathrm{TM}}$, the new standard in emergency cardiac care, call Matrx at $1-800-845-3550$

\section{IIfHE MEDICAL INC.}

Corporate Headquarters/Technical Information Matrx Medical Inc., 145 Mid County Drive

Orchard Park, NY 14127

U.S. (716) $662-6650 \quad(800) 847-1000$

Distribution (800) 845-3550

Canada (800) 876-2879

United Kingdom (0252) 621442 


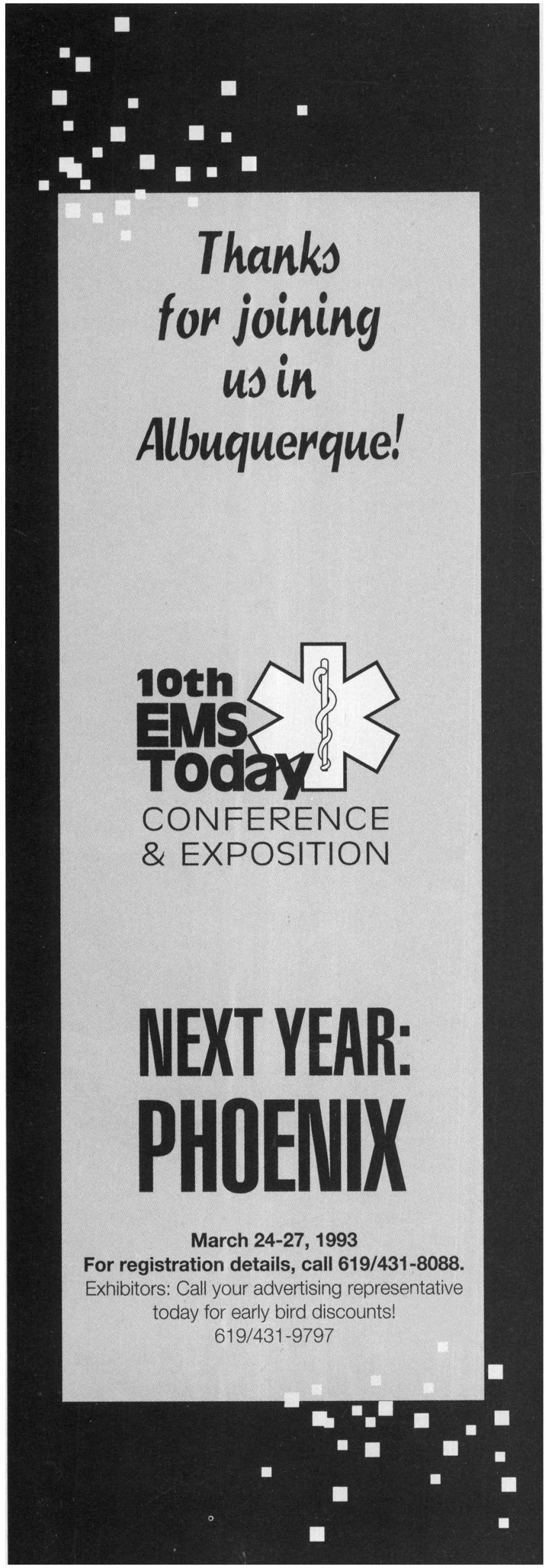

\section{You Con Make A Difierence}

\section{Cervical Spine Issues in Prehospital Medicine}

An educational videotape by Ron Stewart, MD

Every year, 13,000 Americans suffer a spinal cord injury. Of those victims, 8,000 survive thanks to advances in the study of cervical spine issues.

Dr. Stewart examines the history of spinal cord injury (SCI) and presents some startling numbers on the changing face of SCI treatment in the prehospital setting. Learn the facts about SCI and how you can make a difference.

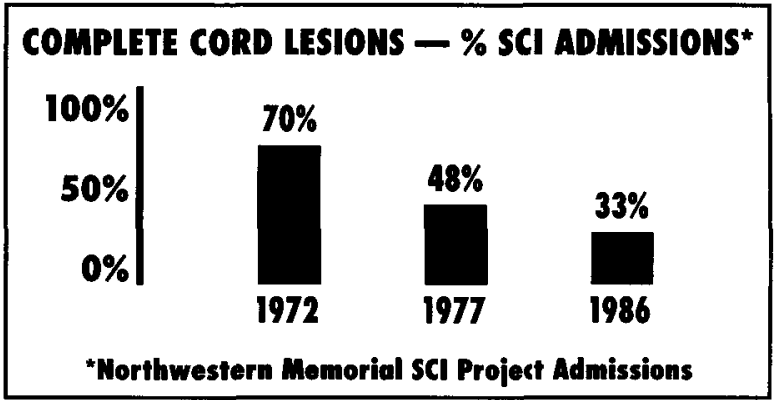

Spinal cord injury (SCI) registries reveal a consistent decline in the number of patients with complete cord lesions presenting to hospitals caring for SCI. In 1972, some 70 percent of patients presenting to major SCI centers had complete cord lesions, compared to 48 percent in 1977 and 33 percent in 1986. Many would attribute much of this decline to improved training, procedures, and equipment of prehospital care personnel.

Cervical Spine Issues in Prehospital Medicine is a non-profit videotape produced by California Medical Products in conjunction with Emergency Medical Update. Proceeds from the sale of every tape go to support research conducted by the National Association of EMS Physicians.

Cervical Spine Issues in Prehospital Medicine $\$ 49.95$

To order, call The Jems Bookstore toll-free 1-800-266-JEMS

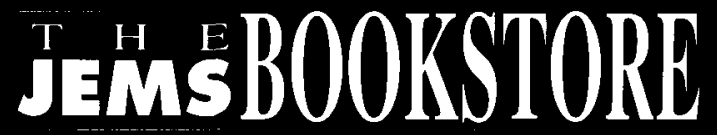

